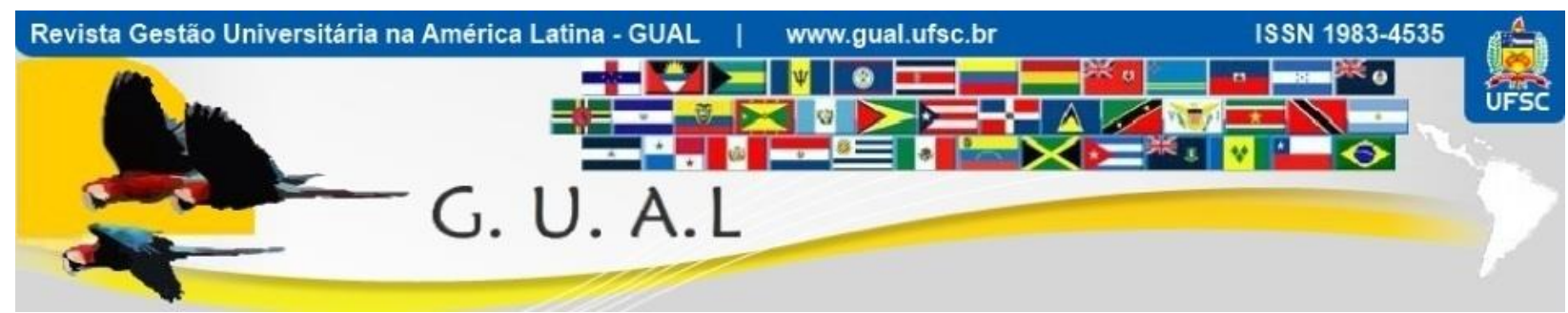

DOI: http://dx.doi.org/10.5007/1983-4535.2014v7n3p1

\title{
CLIMA ORGANIZACIONAL: FATORES SIGNIFICATIVOS NA PERCEPÇÃO DE DOCENTES E DISCENTES VINCULADOS A PROGRAMAS DE PÓS-GRADUAÇÃO
}

\section{ORGANIZATIONAL CLIMATE: SIGNIFICANT FACTORS IN PERCEPTION OF TEACHERS AND STUDENTS LINKED TO POST GRADUATE PROGRAMS}

\author{
Angélica Balconi Moro, Doutora \\ Universidade Federal de Santa Maria - UFSM \\ angelicabalconi@hotmail.com \\ Laércio André Gassen Balsan, Doutorando \\ Universidade Federal de Santa Maria - UFSM \\ laerciobalsan@yahoo.com.br \\ Vânia Medianeira Flores Costa, Doutora \\ Universidade Federal de Santa Maria - UFSM \\ vaniaflores2006@yahoo.com.br \\ Maria Rosa Chitolina Schetinger, Doutora \\ Universidade Federal de Santa Maria - UFSM \\ mariachitolina@gmail.com
}

Recebido em 24/fevereiro/2013

Aprovado em 15/agosto/2014

Sistema de Avaliação: Double Blind Review

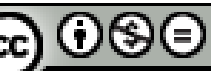

Esta obra está sob uma Licença Creative Commons Atribuição-Uso. 


\title{
CLIMA ORGANIZACIONAL: FATORES SIGNIFICATIVOS NA PERCEPCÃO DE DOCENTES E DISCENTES VINCULADOS A PROGRAMAS DE PÓS-GRADUAÇÃO \\ DOI: http://dx.doi.org/10.5007/1983-4535.2014v7n3p1
}

\begin{abstract}
RESUMO
Este estudo teve como objetivo analisar os fatores significativos do clima organizacional em programas de pós-graduação (PPGs), na percepção de docentes e discentes. Para tanto, realizou-se uma pesquisa exploratória de caráter quantitativo do tipo multi-casos. Participou da pesquisa uma amostra de 200 alunos e 52 professores de quatro PPGs de uma Instituição Pública de Ensino Superior. Os fatores selecionados para a realização deste estudo foram: Relacionamento Interpessoal; Gestão; Envolvimento/Comprometimento; Organização e Condições de trabalho; e, Realização/Satisfação. A análise dos dados demonstrou que alguns fatores, como Relacionamento interpessoal, Gestão, Envolvimento/comprometimento, Realização/satisfação apresentam alto nível de satisfação entre a amostra pesquisada. Já o fator Organização e condições de trabalho necessita atenção especial para a manutenção da satisfação dos indivíduos e consequente melhoria do clima organizacional dos PPGs.
\end{abstract}

Palavras-chave: Clima Organizacional. Programa de Pós-graduação. Docentes. Discentes. Avaliação.

\begin{abstract}
This study aimed to analyze the significant factors of the organizational climate in the Graduate Programs (PPG) under the perception of professors and students. To this aim, we carried out an exploratory and quantitative multi-case study. A sample of 200 students and 52 professors from four PPG of a Public Institution of Higher Education participated in the study. The factors selected for this study were: interpersonal relationships; management; involvement/commitment; organization and working conditions; and achievement/satisfaction. Data analysis showed that factors such as interpersonal relationships, management, involvement/commitment, and achievement/satisfaction had a higher level of satisfaction between the subjects studied. However, the factors organization and working conditions need special attention to maintain the satisfaction of the individuals and the consequent improvement of the organizational climate of PPG.
\end{abstract}

Keywords: Organizational Climate. Post Graduate Program. Professors. Students. Evaluation. 


\section{CLIMA ORGANIZACIONAL: FATORES SIGNIFICATIVOS NA PERCEPCÃO DE DOCENTES E DISCENTES VINCULADOS A PROGRAMAS DE PÓS-GRADUAÇÃO \\ DOI: http://dx.doi.org/10.5007/1983-4535.2014v7n3p1}

\section{INTRODUÇÃO}

As organizações estão vivenciando um processo de grandes e rápidas mudanças em consequência da globalização, do avanço tecnológico e científico e da transformação de valores, o que vem impondo barreiras no seu progresso e dificultando sua permanência no mercado atual. Esse processo ocorre também em Instituições Públicas de Ensino Superior (IES), agravados por outros fatores como a legislação, a burocracia, a cultura e os diversos interesses políticos. Além desses fatores, os programas de pós-graduação são avaliados por órgãos competentes que autorizam ou não seu funcionamento.

A avaliação dos Cursos de pós-graduação stricto sensu é feita pela Coordenação de Aperfeiçoamento de Pessoal de Nível Superior (Capes), órgão que conduz todo o sistema de avaliação de cursos de pós-graduação no país, produzindo indicadores e um sistema de informações que subsidia tanto o processo de regulamentação, como garante transparência dos dados sobre qualidade dos cursos a toda sociedade. O Sistema de avaliação compreende a realização da avaliação dos programas de pós-graduação e a avaliação das propostas de cursos novos de pós-graduação (CAPES, 2012).

A avaliação dos programas de pós-graduação engloba a realização do acompanhamento anual e da avaliação trienal do desempenho de todos os programas e cursos que integram o Sistema Nacional de Pós-graduação (SNPG). Os resultados desse processo são expressos pela atribuição de uma nota na escala de "1" a "7", a qual fundamenta a deliberação sobre quais cursos obterão a renovação de "reconhecimento", a vigorar no triênio subsequente. Já a avaliação das propostas de cursos novos de pós-graduação é realizada para a admissão de novos programas e cursos ao SNPG. Para tanto, a Capes verifica a qualidade de tais propostas e se elas atendem ao padrão de qualidade requerido (CAPES, 2012).

Essas avaliações são baseadas em um conjunto de princípios, diretrizes e normas, que incluem avaliação docente e discente e principalmente a qualidade e quantidade da produção científica. Em vista disso, não apenas professores e alunos, mas todas as pessoas envolvidas nesse processo sofrem pressões para atingir as metas estabelecidas pela Capes, e buscam constantemente formas de obter êxito nesse sistema de avaliação. Dentro desse contexto, a avaliação do clima organizacional surge como um instrumento que permite constatar a realidade interna ao identificar os pontos que afetam o desempenho de professores e alunos na pós-graduação. 


\section{CLIMA ORGANIZACIONAL: FATORES SIGNIFICATIVOS NA PERCEPCÃO DE DOCENTES E DISCENTES VINCULADOS A PROGRAMAS DE PÓS-GRADUAÇÃO \\ DOI: http://dx.doi.org/10.5007/1983-4535.2014v7n3p1}

A partir de análise na literatura, Motta (2006), comenta que é preciso conhecer o clima, a fim de que seja possível: fornecer subsídios para os gestores criarem políticas e diretrizes que se aproximem das expectativas dos indivíduos com foco no objetivo de atender às suas demandas na busca da motivação e do aprendizado; permitir a implantação de um plano de ação, visando melhorias nas condições de trabalho; elaborar estratégias favoráveis às relações e a organização do trabalho e propiciar um ambiente favorável ao alcance dos objetivos. A mesma autora explica ainda que, um clima ruim modifica o ânimo da maioria das pessoas criando um ambiente com discórdias, rivalidades, tensões, desunião, desinteresse, resistência, entre outros. Pessoas que trabalham em um ambiente com clima desfavorável podem apresentar os seguintes comportamentos: trabalham em ritmo lento de produção; apresentam baixo nível de cooperação; demonstram pouca preocupação com a qualidade final da tarefa; desperdiça recursos disponíveis, como: tempo, material, patrimônio, potencial; provocam situações defensivas para preservarem-se criando intrigas, ações hostis, desavenças, desacordos, conflitos, tensões, tornando o ambiente turbulento; desenvolvem atividades baseadas na lógica do medo, da insegurança e de receio de ser punido; estabelecem uma aliança de transgressão à norma e à regra e rompem com a ética no trabalho; demonstram competitividade acirrada e destrutiva e apresentam estratégia oportunista de trabalho.

Segundo Rizzatti (2002), ao avaliar o clima organizacional é possível identificar os pontos fortes e fracos da instituição, facilitando, assim, a implementação das mudanças necessárias para a melhoria do trabalho e para a satisfação das pessoas. A melhoria de qualquer processo depende de uma análise geral e um consequente diagnóstico detalhado. $\mathrm{O}$ processo deve, como um todo, caminhar na direção da formação de profissionais críticos, transformadores, responsáveis e produtivos.

Sendo assim, conhecer o grau de satisfação, as necessidades, aspirações e expectativas do grupo de trabalho constitui-se uma importante ferramenta que beneficia o ambiente de trabalho, promovendo a motivação e, consequentemente, o aprimoramento na qualidade e na produtividade. A avaliação do clima organizacional vai ao encontro desse propósito, pois permite conhecer os pontos fracos, as oportunidades de melhoria e os pontos fortes possibilitando promover ações para que as falhas sejam corrigidas e os fatores positivos reforçados.

Vale lembrar que pesquisas sobre clima organizacional têm merecido maior atenção, contudo, pouco tem se produzido no campo das organizações universitárias (RIZZATI et al., 


\section{CLIMA ORGANIZACIONAL: FATORES SIGNIFICATIVOS NA PERCEPCÃO DE DOCENTES E DISCENTES VINCULADOS A PROGRAMAS DE PÓS-GRADUAÇÃO \\ DOI: http://dx.doi.org/10.5007/1983-4535.2014v7n3p1}

2010). Segundo Rizzatti (2002) nessas organizações, de um modo geral, são desenvolvidos poucos estudos na área de gestão de recursos humanos, ocasionando a ausência de políticas internas e externas adequadas aos interesses sociais. Observa-se assim que existe carência e dificuldades na realização de ações referentes aos fatores que influenciam na produtividade nos PPGs.

Diante do exposto, o presente estudo pretende analisar os fatores significativos do clima organizacional, em programas de pós-graduação (PPGs), na percepção de docentes e discentes. Para tanto, realizou-se uma survey cross-section exploratória de caráter quantitativo. As unidades de análise foram os programas de pós-graduação de Química, Ciências Biológicas: Bioquímica Toxicológica, Matemática e Biodiversidade da Universidade Federal de Santa Maria (UFSM). Foram definidos os seguintes objetivos específicos que balizaram a realização deste estudo: (i) verificar os pontos fortes e fracos dos programas de pós-graduação, (ii) verificar de que forma o clima organizacional é percebido e interpretado pelos docentes e discentes pesquisados e (iii) diagnosticar os fatores que afetam o desempenho dos indivíduos de forma geral nos programas.

\section{REVISÃO DE LITERATURA}

\subsection{INSTITUIÇÃO DE ENSINO SUPERIOR COMO UMA ORGANIZAÇÃO}

Uma organização é considerada uma unidade social intencionalmente constituída, tendo uma finalidade específica. Para Cury (2000) as organizações são caracterizadas pela divisão do trabalho, do poder e das responsabilidades devidamente planejadas para atingir suas finalidades. Toda a organização, seja pública ou privada ou do terceiro setor, possui uma estrutura formal e uma informal, isto é, um grupo de pessoas comprometidas com o intuito de gerar algum tipo de produto ou serviço. Para a estrutura formal dá-se o nome de estrutura organizacional, que dita o funcionamento da instituição e varia de uma para outra.

Conforme Machado e Silveira (1998), as estruturas organizacionais são formas para as organizações alcançarem seus objetivos. Essas estruturas moldam o comportamento dos indivíduos que é resultante de experiências organizacionais convertidas em princípios, valores, normas, regras e crenças. Cury (2000) afirma que uma instituição é um conjunto de pessoas que se utiliza de um aparato técnico e obedece a um conjunto de normas para a consecução de tarefas em comum. Assim, como em qualquer outro tipo de organização, as IES possuem suas estruturas que se assemelham, tanto na área pública como na privada, por 


\section{CLIMA ORGANIZACIONAL: FATORES SIGNIFICATIVOS NA PERCEPCÃO DE DOCENTES E DISCENTES VINCULADOS A PROGRAMAS DE PÓS-GRADUAÇÃO \\ DOI: http://dx.doi.org/10.5007/1983-4535.2014v7n3p1}

serem baseadas em estruturas burocráticas departamentais. Dessa forma, as mesmas são definidas pelo trio que representam suas funções-fim: o ensino, a pesquisa e a extensão. Então, o ensino é a transmissão de conhecimentos. A pesquisa é a produção da atividade científica, através do conhecimento. A extensão distribui na comunidade, sob a forma de cursos e serviços, as atividades de ensino e pesquisa (SCHUCH Jr, 1995).

O local desta pesquisa, os PPGs, são ao mesmo tempo um espaço transdisciplinar, uma entidade universitária, pública e de ensino que se estrutura como organização para atingir objetivos e metas. As buscas pelo cumprimento de normas, de regras e pelo alcance de seus objetivos fazem com que as IES estruturem os processos de trabalho conforme os padrões das gestões administrativas. Assim como uma empresa que elabora produtos e presta serviços à população, às universidades cabe a criação, a transferência e a aplicação de conhecimentos para a formação de cidadãos.

Essas instituições são responsáveis pelo avanço do conhecimento científico e tecnológico na sociedade. Também como uma organização, a universidade deve estar voltada para a satisfação plena das necessidades das pessoas que a constituem a fim de que as metas e os objetivos sejam alcançados. Uma das mais importantes características diferenciais da universidade com relação a outras organizações é a de que ela é formada de pessoas para pessoas. Desse modo, supõe-se que as universidades precisam realizar uma gestão voltada para os seres humanos. De acordo com Mezomo (1994), a qualidade, no âmbito das IES, passa pela qualidade das pessoas que as constituem, pois são essas as responsáveis pelo sucesso ou fracasso de tais instituições.

Além de recursos humanos qualificados, Franco (1997) ensina que são necessários recursos financeiros, tempo para fazer pesquisa, condições básicas de infraestrutura física e um ambiente propício para o desenvolvimento da produção científica. Corroborando com essa idéia, Witter (1997) destaca a importância de, ao avaliar a produção científica, considerar as variáveis do processo, ou seja, considerar o contexto, o produtor, o produto, o consumidor e o impacto em sua especificidade. Portanto, o estabelecimento de um ambiente acadêmico, propício à produção científica, requer a construção de um conjunto de condições favoráveis que contemple todos os envolvidos no processo. 


\section{CLIMA ORGANIZACIONAL: FATORES SIGNIFICATIVOS NA PERCEPCÃO DE DOCENTES E DISCENTES VINCULADOS A PROGRAMAS DE PÓS-GRADUAÇÃO \\ DOI: http://dx.doi.org/10.5007/1983-4535.2014v7n3p1}

\subsection{RELAÇÃO ALUNO-PROFESSOR E A PRODUÇÃO DO CONHECIMENTO}

A produção de conhecimento acadêmico no Brasil, daqui para frente chamada de produção científica ou pesquisa, teve início no século XX. Na sociedade atual, as fontes de poder e riqueza dependem da capacidade de geração de conhecimento e processamento da informação que, por sua vez, dependem da interação entre recursos humanos, infraestrutura tecnológica e inovação organizacional e estrutural. Segundo Santos, Faria e Rurato (2000, p.650), "aprender, ou melhor, ainda, aprender a aprender, constitui o mais importante meio para o progresso, para a constituição da riqueza e do bem-estar pessoal e social, fundando a promoção da capacidade de competir, cooperar e agir...”.

A produção do conhecimento está relacionada à experiência individual e seu meio ambiente cultural. Dessa forma, a relação que se estabelece no ambiente de aprendizagem é descrita da seguinte maneira: A relação entre aluno/aluno(s) e entre professor/aluno(s) é uma tríade, que inclui o objeto de conhecimento a compartilhar e a transmissão das experiências e das aprendizagens dos alunos anteriormente vividas, as quais são enriquecidas pela discussão de pontos de vista (TOSCHI, 2002).

De acordo com Moreira (1998), o relacionamento do professor com seus alunos e a percepção que os alunos têm de seu professor forma a primeira fase de estudos que é decisiva: o aluno busca classificar o professor em termos comportamentais - como acessível ou nãoacessível, motivador ou não-motivador, entre outros. Corroborando com essa ideia, Fontaine (1988), acrescenta que a capacidade intelectual não explica, em média, mais de $25 \%$ da variação dos resultados escolares, por isso é necessário fazer apelo a outros fatores para explicar satisfatoriamente as diferenças de produtividade dos alunos. Ainda de acordo com o mesmo autor, a motivação apresenta-se como o aspecto dinâmico da ação: é o que leva o indivíduo a agir, ou seja, o que o leva a iniciar uma ação, a orientá-la em função de certos objetivos. Portanto, a motivação é um fator que deve ser somado nesse contexto, pois apresenta grande importância na análise do processo educativo.

Para Casassus (1995), outro fator que determina a aprendizagem são as interações/relacionamentos entre os alunos e o professor e também entre os alunos. O autor defende, ainda, que a educação deverá estar centrada nas necessidades de aprendizagem dos alunos e na criação de um clima educacional que os torne responsáveis por sua trajetória. 


\section{CLIMA ORGANIZACIONAL: FATORES SIGNIFICATIVOS NA PERCEPCÃO DE DOCENTES E DISCENTES VINCULADOS A PROGRAMAS DE PÓS-GRADUAÇÃO \\ DOI: http://dx.doi.org/10.5007/1983-4535.2014v7n3p1}

\subsection{CLIMA ORGANIZACIONAL}

As IES são consideradas organizações extremamente complexas formadas por vários segmentos, divididos em corpo docente, corpo discente, corpo técnico-administrativo e público em geral, cada qual com seus próprios interesses e preocupações. Dessa forma, a instituição que esteja preocupada com a sua sobrevivência deve direcionar seu foco para entender o que as pessoas sentem, esperam, aspiram, percebem, bem como o que as motiva, pois se sabe que a produtividade da mesma é também o resultado do clima organizacional e estado de espírito dos indivíduos que dela fazem parte. Segundo Rizzatti (2002), nas universidades, um dos fatores que deve ser repensado relaciona-se com a melhoria no ambiente de trabalho e a satisfação dos seus múltiplos usuários em relação ao clima presente na instituição. Elucidando perfeitamente o que se discute a respeito do assunto, Bressoux (2003) cita Fox (1973) que diz que o clima em uma escola resulta dos processos utilizados e das condições ambientais. O clima determina a qualidade de vida e a produtividade dos docentes e discentes. Ele é crítico para a saúde e para a eficácia de uma organização.

No final de 2002, os países que fazem parte do Laboratório Latino-americano de Avaliação da Qualidade da Educação (LLECE) da Orealc/Unesco desenvolveram o Segundo Estudo Regional Comparativo e Explicativo (SERCE), que capitalizou o que foi feito e aprendido com o primeiro estudo. Aquele teve como objetivo melhorar a qualidade da educação e dos sistemas educacionais da América Latina e do Caribe. A partir dos resultados obtidos, o SERCE concluiu que o clima escolar é a variável que maior influência exerce sobre o rendimento dos estudantes (SERCE, 2009).

De acordo com Leitão et al. (1998), o clima organizacional é importante para a produtividade, na medida em que interfere diretamente na satisfação, na motivação e na criatividade das pessoas. Afirma ainda que os estudos nessa área são particularmente úteis porque fornecem um diagnóstico da organização, bem como as indicações de áreas carentes de atenção especial. Ainda, segundo Luz (2003), o clima de uma instituição é o reflexo dos indivíduos que a compõe, dos seus processos de trabalho, das formas de comunicação, bem como as relações estabelecidas entre os agentes organizacionais. A maneira como a qual a empresa é percebida pelos seus componentes cria uma atmosfera psicológica que atinge diretamente a produtividade dos mesmos. De acordo com o mesmo autor, um dos motivos para se avaliar o clima organizacional é porque o desempenho dos recursos humanos afeta o 


\section{CLIMA ORGANIZACIONAL: FATORES SIGNIFICATIVOS NA PERCEPCÃO DE DOCENTES E DISCENTES VINCULADOS A PROGRAMAS DE PÓS-GRADUAÇÃO \\ DOI: http://dx.doi.org/10.5007/1983-4535.2014v7n3p1}

desempenho organizacional e porque o desempenho dos recursos humanos é afetado pelo clima organizacional.

O estudo do clima organizacional traz informações sobre a motivação e a satisfação das pessoas. Desconhecer essas informações pode afetar fatores como eficiência, desempenho e produtividade da organização, pois quanto mais satisfeitos e motivados os indivíduos, maior o rendimento e a qualidade do trabalho. Rizzatti (2002) explica que o clima organizacional refere-se às propriedades motivacionais do ambiente organizacional. Luz (1995) complementa que o clima organizacional retrata o grau de satisfação material e emocional das pessoas no trabalho, sendo que um clima favorável propicia um bom relacionamento entre os membros.

Segundo Costa (2003), o clima é definido como um conjunto de práticas e valores que caracterizam uma unidade de pensamento e ação entre os membros da organização. Ele refere-se ao ambiente interno estabelecido entre os participantes da empresa (Magro, 2005) e é decorrente das interações entre os indivíduos e a forma como esses se comportam (SCHNEIDER e REICHERS, 1983).

A pesquisa de clima é importante, pois fornece subsídios acerca de como as pessoas se comportam (SCHNEIDER e REICHERS, 1983) e reflete quais as necessidades da organização e das pessoas que estão sendo atendidas (CODA, 1993). Tais subsídios podem ser usados para melhorar a relação entre os indivíduos (SANDES, 2001), bem como, diversos processos presentes na instituição (RIZZATTI, 2002). Assim, conforme Krum (2005), o ambiente de trabalho deve ser favorável para que o professor/aluno organize e reorganize os dados e as informações, direcionando-se para a solução e encaminhamento de uma situaçãoproblema. Dessa forma, o suporte fornecido ao indivíduo é um dos fatores que asseguram o alcance dos objetivos, como também a superação dos índices de produtividade estabelecidos.

\section{METODOLOGIA}

Trata-se de uma survey cross-section de caráter quantitativo-exploratório. De acordo com Gil (2010) e Lazzarini (1995), a pesquisa exploratória proporciona uma maior familiaridade com o problema a fim de torná-lo mais claro e compreensível. Também serve para explorar problemas pouco conhecidos, permitindo assim uma maior flexibilidade em seu planejamento.

Este estudo foi realizado em quatro PPGs da Universidade Federal de Santa Maria, localizada na região central do Rio Grande do Sul. A escolha desses PPGs como objeto de 


\section{CLIMA ORGANIZACIONAL: FATORES SIGNIFICATIVOS NA PERCEPCÃO DE DOCENTES E DISCENTES VINCULADOS A PROGRAMAS DE PÓS-GRADUAÇÃO \\ DOI: http://dx.doi.org/10.5007/1983-4535.2014v7n3p1}

estudo atendeu às seguintes motivações: (i) pela importância que a UFSM representa para região onde está situada com relação ao papel social que desempenha, (ii) pelos PPGs exportarem conhecimento e recursos humanos qualificados para todo o território nacional, (iii) pelas pressões e metas estabelecidas pela Capes; (iv) por visarem uma produção qualificada do conhecimento científico e tecnológico, (v) pela facilidade de acesso e (vi) os quatro programas escolhidos apresentam características distintas conforme pode ser visualizado na Tabela 1. Optou-se por programas com características diferentes com o objetivo de manter a acurácia amostral, diminuindo-se os vieses de superestimativa e subestimativa (COOPER e SCHINDLER, 2011).

Tabela 1 Características dos Programas de Pós-graduação objetos de estudo

\begin{tabular}{lllll}
\hline Características & PPGMat & PPGBA & PPGBT & PPGQ \\
\hline Conceito de aval. CAPES & 3 & 4 & 5 & 7 \\
Ano de Início & 2007 & 2003 & 1998 & 1985 \\
Anos de existência & 4 & 8 & 13 & 26 \\
\hline
\end{tabular}

Fonte: Dados da pesquisa

Para a realização da coleta de dados optou-se como instrumento pelo questionário. Foram utilizados dois questionários: um para coletar os dados do público docente e outro para coletar os dados do público discente. Esses instrumentos foram compostos por duas partes: uma composta por 7 questões referentes aos dados de identificação, e outra referente ao clima organizacional que foi construída com base na metodologia de Luz (2003) e Rizzatti (2002) e adaptada à realidade dos PPGs em questão. Para os docentes a segunda parte dos questionários ficou composta por 55 afirmativas fechadas, enquanto que para os discentes por 74 questões afirmativas fechadas.

Optou-se pelo questionário, pois de acordo com Cervo et al. (2006) o mesmo possibilita medir com mais exatidão o que se deseja.

Para a medição do nível de concordância com as afirmativas da segunda parte dos questionários, utilizou-se uma escala do tipo Likert, de cinco pontos, onde a atribuição do número 1 representa "Discordo totalmente", 2 "Discordo um pouco", 3 "Não concordo, nem discordo", 4 "Concordo um pouco" e o número 5, "Concordo totalmente".

O questionário foi submetido à validação semântica e de conteúdo através de uma avaliação por três especialistas, pesquisadores da área. Esses avaliaram o conteúdo e a forma dos questionários quanto a sua clareza, objetividade e precisão de linguagem. 


\section{CLIMA ORGANIZACIONAL: FATORES SIGNIFICATIVOS NA PERCEPCÃO DE DOCENTES E DISCENTES VINCULADOS A PROGRAMAS DE PÓS-GRADUAÇÃO \\ DOI: http://dx.doi.org/10.5007/1983-4535.2014v7n3p1}

Após a aprovação pelo Comitê de Ética (Protocolo CEP-UFSM: 23081.008061/201048), consideraram-se os ensinamentos de Malhotra (2006), que defende a pré-testagem dos questionários para eliminar possíveis defeitos. O pré-teste foi realizado com um grupo de 2 alunos e um professor de cada programa. O objetivo desse processo foi verificar as possíveis inconsistências (complexidade das questões, imprecisão na redação, questões desnecessárias, constrangimentos ao informante, exaustão, dentre outras) que o instrumento de coleta de dados poderia apresentar e, assim, identificar possíveis melhorias no mesmo. É importante destacar que os dados do pré-teste não foram considerados na amostra. Para a realização da coleta dos dados e do pré-teste, foi feito, inicialmente, um contato com a coordenação dos PPGs avaliados, visando explicar o objetivo desta pesquisa, apresentar o questionário e o procedimento para sua aplicação.

A consistência interna do questionário foi medida por meio do alpha de cronbach. A confiabilidade mostra até que ponto uma escala produz resultados consistentes (MALHOTRA, 2006). Na presente pesquisa, obteve-se um alpha de Cronbach igual a 0,951 para a escala de clima organizacional aplicada aos alunos e 0,894 para a escala aplicada aos professores, esses índices são considerados muito satisfatórios de acordo com Hair et al. (2005).

Participaram da pesquisa 200 alunos de mestrado e doutorado e 52 professores, escolhidos aleatoriamente segundo o número de indivíduos de cada programa pela técnica de amostragem estratificada proporcional, a qual é caracterizada pela seleção de uma parcela de cada subgrupo considerado (GIL, 2010). No caso específico, os estratos foram os quatro programas selecionados. De acordo com Gil (2010), esse tipo de amostragem tem como principal vantagem o fato de assegurar representatividade de acordo com os critérios adotados para a estratificação. O cálculo do tamanho da amostra levou em consideração um nível de confiança de $95 \%$ e admitiu-se um erro de 4\%. Na Tabela 2 demonstra-se a amostra pesquisada.

Tabela 2 Amostra da pesquisa

\begin{tabular}{llllll}
\hline & PPGMat & PPGBA & PPGBT & PPGQ & TOTAL \\
\hline Alunos de Mestrado & 12 & 16 & 21 & 47 & 96 \\
Alunos de Doutorado & 0 & 12 & 44 & 48 & 104 \\
Professores & 10 & 10 & 16 & 16 & 52 \\
\hline TOTAL & $\mathbf{2 2}$ & $\mathbf{3 8}$ & $\mathbf{8 1}$ & $\mathbf{1 1 1}$ & $\mathbf{2 5 2}$ \\
\hline
\end{tabular}

Fonte: Dados da pesquisa 


\section{CLIMA ORGANIZACIONAL: FATORES SIGNIFICATIVOS NA PERCEPCÃO DE DOCENTES E DISCENTES VINCULADOS A PROGRAMAS DE PÓS-GRADUAÇÃO \\ DOI: http://dx.doi.org/10.5007/1983-4535.2014v7n3p1}

A aplicação dos instrumentos ocorreu de forma coletiva, realizada nas salas de aulas, laboratórios e salas de permanência dos alunos e professores e somente com aqueles que haviam assinado o Termo de Compromisso Livre e Esclarecido. Foi reforçado aos participantes do estudo, que lhes seriam assegurados o anonimato e a privacidade resguardando-lhes o direito, inclusive, de não responderem ao questionário, se assim o desejassem.

Os dados coletados foram informatizados em arquivo eletrônico por meio do software Excel e analisados com o auxílio do pacote estatístico SPSS (Statistical Package for the Social Sciences), versão 15.0 para Windows.

Realizaram-se análises descritivas (de tendência central e de dispersão) e exploratórias para investigar a exatidão da entrada dos dados. A estatística descritiva permitiu identificar os fatores significativos de clima organizacional resultantes das respostas de cada indivíduo. Os dados intervalares foram transformados em dados categóricos. A categorização dos dados levou em conta o cálculo da média das respostas dos indivíduos em relação à escala Likert de 5 pontos utilizada no questionário. De posse das médias de cada construto, as mesmas foram categorizadas dentro de três níveis diferentes (Pontos fracos, Pontos a melhorar e Pontos fortes), conforme descrito no Quadro 1.

\begin{tabular}{|l|c|c|c|c|c|}
\hline & $\begin{array}{c}\text { Discordo } \\
\text { Totalmente }\end{array}$ & $\begin{array}{c}\text { Discordo } \\
\text { um Pouco }\end{array}$ & $\begin{array}{c}\text { Não concordo, } \\
\text { nem discordo }\end{array}$ & $\begin{array}{c}\text { Concordo um } \\
\text { Pouco }\end{array}$ & $\begin{array}{c}\text { Concordo } \\
\text { Totalmente }\end{array}$ \\
\hline Escala Likert & 1 & 2 & 3 & 4 & 5 \\
\hline Média & \multicolumn{2}{|c|}{1,00 a 2,99} & 3,00 a 3,99 & 4,00 a 5,00 \\
\hline Escala & \multicolumn{2}{|c|}{ Pontos fracos } & Pontos a melhorar & \multicolumn{2}{c|}{ Pontos fortes } \\
\hline
\end{tabular}

Quadro 1 Categorização dos dados.

Fonte: elaborado pelos autores.

\section{RESULTADOS}

$\mathrm{Na}$ amostra dos alunos dos quatro programas avaliados, prevaleceu o sexo feminino com um percentual de $60 \%$. Já na amostra dos professores, o sexo predominante foi o masculino (56\%). A faixa etária da maioria dos alunos (88\%) está entre 20 a 31 anos, enquanto a maioria (73\%) dos professores está entre 38 a 49 anos. Dos alunos avaliados $48 \%$ cursam mestrado e $52 \%$ cursam doutorado, sendo que a maioria (80\%) está entre o primeiro e quarto semestre. Ou seja, em fase inicial do doutorado ou concluindo o mestrado. Em relação ao nível de formação dos professores dos programas avaliados, $67 \%$ dos professores possuem doutorado e $33 \%$ pós-doutorado. 


\section{CLIMA ORGANIZACIONAL: FATORES SIGNIFICATIVOS NA PERCEPCÃO DE DOCENTES E DISCENTES VINCULADOS A PROGRAMAS DE PÓS-GRADUAÇÃO \\ DOI: http://dx.doi.org/10.5007/1983-4535.2014v7n3p1}

Destaca-se que a maioria (78\%) dos alunos possui bolsa de estudos das agências financiadoras Coordenação de Aperfeiçoamento de Pessoal de Nível Superior (CAPES) e do Conselho Nacional de Desenvolvimento Científico e Tecnológico (CNPq). Em relação ao tempo de atividade no programa, a maioria dos professores (40\%) está no PPG a menos de cinco anos.

Em relação aos fatores de clima organizacional significativos na percepção dos docentes e discentes ressalta-se que quanto maior o escore no item, mais satisfeito está o indivíduo. Ou seja, a resposta com valor 5 indica concordância plena e a 1 discordância extrema. Desse modo, pode-se observar na Tabela 3 um sentimento de satisfação por parte dos indivíduos pesquisados. Como apresentado nessa Tabela, apenas foi encontrado um fator a ser melhorado, tomando-se por base a categorização convencionada. $\mathrm{O}$ fator organização $e$ condição de trabalho teve uma média igual a 3,66 ficando dentro da categorização que vai desde 3 até 3,99. Assim, esse fator exige atenção especial para a manutenção da satisfação dos indivíduos.

Por meio dos dados, nota-se que existe uma relação entre a percepção dos alunos e professores. Percebe-se que quanto maior a satisfação do professor em determinado fator maior é a satisfação apresentada pelos estudantes. Desse modo, sugere-se que em programas de pós-graduação os docentes e discentes percebem o clima organizacional de forma muito semelhante em suas diferentes dimensões.

Tabela 3 Fatores significativos na percepção dos docentes e discentes.

\begin{tabular}{c|c|c|c|c|c|c}
\hline \multirow{2}{*}{ Curso } & & $\begin{array}{c}\text { Felacionamento } \\
\text { interpessoal }\end{array}$ & Gestão & $\begin{array}{c}\text { Envolvimento/ } \\
\text { Comprometime } \\
\text { nto }\end{array}$ & $\begin{array}{c}\text { Organização e } \\
\text { condições de } \\
\text { trabalho }\end{array}$ & $\begin{array}{c}\text { Realização / } \\
\text { Satisfação }\end{array}$ \\
\hline \multirow{2}{*}{ Bioquímica } & Aluno & 4,14 & 4,10 & 4,55 & 3,53 & 4,33 \\
\cline { 2 - 7 } & Prof. & 4,14 & 4,02 & 4,47 & 3,22 & 4,26 \\
\hline \multirow{3}{*}{ Química } & Aluno & 3,97 & 3,91 & 4,48 & 3,73 & 4,29 \\
\cline { 2 - 7 } & Prof. & 3,88 & 3,63 & 4,38 & 3,56 & 4,14 \\
\hline \multirow{2}{*}{ Biodiversidade } & Aluno & 4,13 & 4,53 & 4,56 & 3,97 & 4,45 \\
\cline { 2 - 7 } & Prof. & 3,88 & 4,40 & 4,43 & 3,87 & 4,23 \\
\hline & Aluno & 4,03 & 4,04 & 4,49 & 3,62 & 4,35 \\
\hline \multirow{2}{*}{ Grof. } & 4,11 & 4,55 & 4,68 & 3,76 & 4,51 \\
\hline & Aluno & 4,07 & 4,14 & 4,52 & 3,71 & 4,35 \\
\cline { 2 - 7 } & Prof. & 4,00 & 4,15 & 4,49 & 3,60 & 4,28 \\
\hline
\end{tabular}

Fonte: dados da pesquisa 


\section{CLIMA ORGANIZACIONAL: FATORES SIGNIFICATIVOS NA PERCEPCÃO DE DOCENTES E DISCENTES VINCULADOS A PROGRAMAS DE PÓS-GRADUAÇÃO \\ DOI: http://dx.doi.org/10.5007/1983-4535.2014v7n3p1}

Além do "escore" total obtido por alunos e professores, foram analisados cada item do instrumento individualmente, com o objetivo de se identificar aqueles itens considerados como críticos, uma vez que a maioria dos itens foram considerados como sendo favoráveis ao clima organizacional, de acordo com a percepção dos docentes e discentes. Por meio dessa análise, observou-se que o fator Relacionamento interpessoal, fator esse que evidencia o nível de integração e relação entre os alunos, entre os professores e entre alunos e professores, apresentou um elevado grau de satisfação $(\bar{x}=4,03)$, indo ao encontro dos resultados obtidos por Fortes et al. (2011). Os autores verificaram, em um estudo realizado em uma IES, que $67 \%$ dos docentes consideraram o relacionamento bom, $26 \%$ excelente e $7 \%$ consideraram que o relacionamento é mediano. Para Fortes et al. (2011), um nível satisfatório de relacionamento provoca um bem estar no clima organizacional entre os indivíduos. Silva (2003) reforça dizendo que indiscutivelmente o relacionamento impacta na qualidade do clima, devendo ser dada especial atenção a esse fator, para que se crie um ambiente propício ao desenvolvimento das relações interpessoais.

$\mathrm{O}$ item "Existe no programa um relacionamento de integração entre os laboratórios e linhas de pesquisa" obteve média de 2,69 entre os alunos e média de 2,6 entre os docentes. A falta de integração entre as linhas de pesquisas e laboratórios existentes nos programas reprime uma maior produção científica por meio da coautoria entre os pesquisadores. Além disso, muitas vezes o difícil acesso aos diferentes laboratórios impossibilita a utilização de métodos e equipamentos diferenciados. Dentro das instituições públicas, o não compartilhamento de materiais resulta num maior gasto aos cofres públicos, visto que muitas vezes existe uma multiplicidade de aquisições de um mesmo material.

No que se refere ao fator Gestão, constatou-se que ele foi considerado positivo por parte dos professores e alunos. Essa constatação foi reforçada pelos indivíduos, quando eles são questionados sobre o empenho dos gestores na busca do crescimento do programa e sobre a eficiência e eficácia da gestão dos recursos financeiros do programa e por dar ênfase à realização de um bom trabalho, atribuindo importância a altos padrões de desempenho. Nesse sentido, o alto prestígio da gestão pode favorecer a integração entre a administração e os administrados.

Dentro desse fator, os professores demonstraram insatisfação com os itens: "No programa todos os professores são tratados com respeito, independente de suas opiniões"; "A gestão do programa explica adequadamente o motivo das decisões tomadas"; "Existe 


\section{CLIMA ORGANIZACIONAL: FATORES SIGNIFICATIVOS NA PERCEPCÃO DE DOCENTES E DISCENTES VINCULADOS A PROGRAMAS DE PÓS-GRADUAÇÃO \\ DOI: http://dx.doi.org/10.5007/1983-4535.2014v7n3p1}

cooperação entre a gestão e os professores do programa"; e "O processo de gestão do programa é democrático". Todos esses itens ficaram definidos como fatores a serem melhorados. Para Fortes et al. (2011) a participação dos colaboradores nas decisões de determinado ponto ou de assuntos relevantes aos PPGs é algo que deve ser estimulado no ambiente organizacional.

Entre os alunos o item "Os professores do programa são abertos a receber e reconhecer as opiniões e contribuições dos alunos" obteve média igual 3,73. Esse resultado vai ao encontro de Rizzati (2010) que indica que a prática da liderança foi considerada razoável, seja no acompanhamento do trabalho, seja na aceitação de sugestões. Nesse contexto, os professores, nos papéis de lideres dos alunos, devem ficar mais abertos a reconhecer as opiniões dos mesmos para que esses se sintam parte da organização. Fortes et al. (2011) ensinam que o ideal é que os objetivos e metas sejam definidos em conjunto, para um melhor conhecimento dos acontecimentos. Além disso, os autores dizem que a disseminação das ações é fundamental. Para Silva (2003) uma boa comunicação é fundamental para as boas relações humanas e também para o sucesso da organização. Para a autora, a comunicação pode ser uma das maiores causadoras de conflitos em uma organização afetando o clima. Por outro lado, se bem empregada, pode elevar o moral das pessoas.

A pesquisa mostra que o fator "Envolvimento/comprometimento" teve um alto índice de satisfação entre os docentes e discentes, contribuindo para um clima harmônico. Mesmo que só o envolvimento e o comprometimento não garantam o sucesso e o alcance dos objetivos organizacionais, Muller et al. (2005) e Rego e Souto (2004) advogam que um indivíduo comprometido se esforçará mais para atingir os objetivos da organização. Observase que esse sentimento é benéfico tanto para a organização como para o indivíduo, pois esse conceito está ligado ao bem estar no trabalho e com a satisfação com o mesmo (FERRAZ e SIQUEIRA, 2006).

O fator "Organização e condições de trabalho" é um ponto a melhorar dentro dos PPGs pesquisados. Dentre os fatores analisados foi o único que apresentou média inferior a 3,99. Os pontos fortes relatados se resumem na organização temporal e no conhecimento necessário para a realização das atividades e das pesquisas.

No mais, os pontos a melhorar estão relacionados à falta de equipamentos necessários para a realização das atividades $(\bar{x}=3,59$ para alunos e $\bar{x}=3,73$ para professores respectivamente). O espaço físico e as condições físicas (temperatura, higiene, ruído, 


\section{CLIMA ORGANIZACIONAL: FATORES SIGNIFICATIVOS NA PERCEPCÃO DE DOCENTES E DISCENTES VINCULADOS A PROGRAMAS DE PÓS-GRADUAÇÃO \\ DOI: http://dx.doi.org/10.5007/1983-4535.2014v7n3p1}

iluminação entre outros) também se demonstraram inadequados para execução das pesquisas. Outro item que demonstrou descontentamento foi a falta de manutenção dos equipamentos $\left(\bar{x}=3,2375\right.$ entre os alunos e ${ }^{\bar{x}}=3,31$ entre os professores). De acordo com Castro e Dalmaz (2008) a manutenção das condições físicas, nos órgãos públicos, é afetada pela disfunção da burocracia, pois os processos seguem uma legislação específica para a aquisição de bens e serviços que provoca uma morosidade no atendimento das solicitações e necessidades, gerando certo descontentamento entre as pessoas.

Os alunos consideraram os recursos disponibilizados pelos programas insuficientes tanto para a participação em eventos científicos como para o financiamento da pesquisa. Lacerda et al. (2008) considera que os eventos científicos criam a possibilidade de interação entre os estudantes e os profissionais da área, e favorece o acesso a novas informações. Os eventos são muito importantes no processo da disseminação científica, na medida em que a transmissão de ideias e fatos novos chega ao conhecimento da comunidade científica de maneira mais rápida que aquelas veiculadas pelos meios formais de comunicação. Além disso, os eventos científicos constituem-se em um meio de enriquecer o currículo, difusão do conhecimento e para o desenvolvimento de parcerias entre os pesquisadores, assim como se constituem em oportunidade para a tão almejada internacionalização dos programas.

Em relação ao fator "Realização/satisfação", os alunos e professores se demonstraram satisfeitos em fazer parte dos programas em que atuam e declararam que o trabalho realizado proporciona satisfação pessoal e profissional, sentindo-se orgulhosos de fazer parte dos PPGs. Os resultados aqui obtidos corroboram com os resultados de Fortes et al. (2011) e Castro e Dalmaz (2008). Em sua pesquisa os autores identificaram que a grande maioria dos docentes se sentem realizados profissionalmente. O elevado grau de satisfação dos colaboradores indica que as necessidades dos indivíduos estão sendo atendidas de forma a impulsionar e motivar os indivíduos. Apesar do alto índice de satisfação os professores demonstraram-se descontentes com o item: "Eu me sinto satisfeito com o volume de trabalho que realizo" $(\overline{\mathbf{x}}=3,77)$. Esse item merece especial atenção, uma vez que os problemas de saúde dos docentes estão intimamente ligados ao excesso de trabalho e ao acumulo de exigências (ESTEVE, 1999). 


\section{CLIMA ORGANIZACIONAL: FATORES SIGNIFICATIVOS NA PERCEPCÃO DE DOCENTES E DISCENTES VINCULADOS A PROGRAMAS DE PÓS-GRADUAÇÃO \\ DOI: http://dx.doi.org/10.5007/1983-4535.2014v7n3p1}

\section{CONCLUSÕES}

As conclusões apresentadas prestam-se à análise sobre as percepções dos docentes e discentes dos programas de pós-graduação pesquisados, em relação aos fatores significativos do clima organizacional. A amostra foi representativa e os objetivos delineados na pesquisa foram alcançados. Com base no objetivo geral da pesquisa: analisar os fatores significativos do clima organizacional, em programas de pós-graduação (PPGs), na percepção de docentes e discentes chegou-se aos seguintes aspectos conclusivos.

Verificou-se um sentimento de satisfação em relação ao clima organizacional por parte dos indivíduos pesquisados. Dos cinco fatores pesquisados apenas um fator (Organização e condições de trabalho) necessita atenção especial para a manutenção da satisfação dos indivíduos e para a consequente melhoria do clima organizacional. Também foi possível notar a existência de uma relação entre a percepção dos alunos e professores. Ou seja, quanto maior a satisfação do professor em determinado fator, maior é a satisfação apresentada pelos estudantes e vice-versa. Desse modo, sugere-se que em programas de pós-graduação os docentes e discentes percebem o clima organizacional de forma muito semelhante em suas diferentes dimensões.

No tocante ao fator Relacionamento interpessoal, a satisfação dos indivíduos foi considerada boa, visto que se aproxima do ponto máximo de satisfação. Conclui-se que para os pesquisados os aspectos como o nível de integração entre pessoas, bom relacionamento, liberdade para expor pontos de vista, respeito mútuo, liberdade de expressar opiniões e amizade apresentam-se num nível satisfatório para o bom andamento das atividades. Ao serem questionados sobre o relacionamento entre os laboratórios e linhas de pesquisa, alunos e professores se revelaram insatisfeitos. Verificou-se que nos programas os alunos e professores têm uma obsessão por melhorar seu currículo, sendo notável nos programas uma competitividade muito grande entre os grupos de pesquisa e até mesmo entre colegas.

Com relação ao fator Gestão, os docentes e discentes estão altamente satisfeitos. Vislumbram boas práticas de gestão, em razão do empenho e dos incentivos oferecidos. No entanto, os professores demonstraram insatisfeitos com a forma autoritária dos gestores e com a falta de informação sobre a motivação das decisões tomadas. Em relação ao Envolvimento/comprometimento, os docentes e discentes também se revelam bastante comprometidos, demonstrando envolvimento na realização de suas tarefas. 


\section{CLIMA ORGANIZACIONAL: FATORES SIGNIFICATIVOS NA PERCEPCÃO DE DOCENTES E DISCENTES VINCULADOS A PROGRAMAS DE PÓS-GRADUAÇÃO \\ DOI: http://dx.doi.org/10.5007/1983-4535.2014v7n3p1}

$\mathrm{Na}$ presente pesquisa o fator Organização e condições de trabalho é o fator que apresenta maior insatisfação, ficando abaixo do desejável. Verificou-se descontentamento com a falta de equipamentos, espaço físico inadequado, falta de manutenção e falta de incentivo financeiro para a realização das pesquisas.

Em relação ao fator Realização/satisfação os alunos e professores se demonstraram satisfeitos em fazer parte dos programas em que atuam e declararam que o trabalho realizado proporciona satisfação pessoal e profissional, sentindo-se orgulhosos de fazer parte dos PPGs. Apesar do alto índice de satisfação os professores demonstraram-se descontentes com a elevada carga de trabalho. Essa problemática exige atenção, pois os problemas de saúde dos docentes está intimamente ligado ao excesso de trabalho (ESTEVE, 1999).

Concluiu-se, portanto, que a melhoria do clima, nos PPGs em questão, pode ser buscada em quatro frentes:

a) melhorar o relacionamento entre os laboratórios e linhas de pesquisa;

b) reavaliação da gestão organizacional, tornando-a num processo mais participativo, a fim de diminuir as incertezas que os colaboradores têm a cerca das decisões tomadas;

c) redimensionar a carga de trabalho docente, de modo a melhorar sua qualidade de vida;

d) criar estratégias de captação de recursos para compra de equipamentos, bem como a manutenção dos mesmos e financiamento à pesquisa.

As conclusões aqui relatadas podem ser utilizadas para a melhoria da produtividade e da qualidade dos programas. As estratégias podem ser traçadas visando à valorização dos pontos positivos e reestruturação dos pontos fracos, a fim de que os programas sejam bem avaliados pela Capes.

A principal limitação desse estudo refere-se à generalização, pois foram pesquisados apenas quatro programas de pós-graduação. Outra limitação é decorrente da estratégia de pesquisa, uma vez que o estudo exploratório constitui-se em um primeiro passo para estudos futuros que verificarão as hipóteses aqui levantadas. Mesmo assim, esta pesquisa permitiu a familiarização com o objeto estudado, nesse caso, os PPGs e os fatores significativos do clima organizacional abrindo caminho para estudos futuros. Sugere-se assim, estudos confirmatórios dos achados aqui relatados. Também se sugere pesquisas que explorem mais profundamente o universo dos PPGs, principalmente pela importância desses para o desenvolvimento científico e tecnológico do país. 


\section{REFERÊNCIAS BIBLIOGRÁFICAS}

BRESSOUX, P. As pesquisas sobre o efeito-escola e o efeito-professor. Educação em Revista. Belo Horizonte, n. 38, p. 17-38, 2003.

CAPES. Coordenação de Aperfeiçoamento de Pessoal de Ensino. Avaliação da pósgraduação. Disponível em: <http://www.capes.gov.br/avaliacao/avaliacao-da-pos-graduacao $>$ Acesso em: 19 mai. 2012.

CASASSUS, J. Tarefas da educação. Campinas: Autores Associados, 1995.

CASTRO, M. de; DALMAZ, T. Avaliação do clima organizacional em uma universidade pública. Revista eletrônica Latu Sensu. Unicentro, ed. 6, p 1 -19, 2008.

CERVO, A. L.; BERVIAN, P. A.; DA SILVA, R. Metodologia Científica. 6.ed. São Paulo: Pearson Prentice Hall, 2006.

CODA, R. Estudo sobre clima organizacional traz contribuição para aperfeiçoamento de pesquisa na área de RH. Revista de Administração, São Paulo, n. 75, dez., 1993.

COSTA, J. A. Imagens organizacionais da escola. 3. ed. Porto: Edições Asa, 2003.

COOPER, D. R.; SCHINDLER, P. S. Métodos de pesquisa em administração. 10 ed. Porto Alegre: Bookman, 2011.

CURY, A. Organização, sistemas e métodos: uma visão holística. 7. ed. São Paulo: Atlas, 2000 .

ESTEVE, J. M. Mal-estar docente: a sala de aula e a saúde dos professores. São Paulo: Edusc, 1999.

FRANCO, M. E. D. P. Universidade, pesquisa e inovação: o Rio Grande do Sul em perspectiva. Passo Fundo: Ediupf, 1997.

Ferraz, C. R.; Siqueira, M. M. M. Bem-estar no trabalho: estudo com uma amostra de professores. Trabalho apresentado no IV GIBEST - Grupo Interinstitucional de Pesquisa Bem-Estar, Suporte e Trabalho. Uberlândia, MG, 2006.

FONTAINE, A. M. Motivação e realização escolar em função do contexto social. Revista Portuguesa de Pedagogia, v. 22, p. 313-336, 1988.

FORTES, V. C.; FILHO, A. C. B.; CORREIA, M. R.; SANTOS, R. B. C. dos. Clima organizacional em Instituição de Ensino Superior (IES): a percepção dos docentes. In: VII congresso nacional de excelência em gestão, Rio de Janeiro. Anais... Rio de Janeiro, 2011.

GIL, A. C. Métodos e técnicas de pesquisa social. São Paulo: Atlas, 2010. 
HAIR, J. Jr.; MONEY, A.; BABIN, B.; SAMOUEL, P. Fundamentos de Métodos de pesquisa em administração. Porto Alegre: Bookman, 2005.

KRUM, D. Psicologia do trabalho. Rio de Janeiro: LTC, 2005.

LACERDA, A. L. de; WEBER, C.; PORTO, M. P.; SILVA, R. A. da. A importância dos eventos científicos na formação acadêmica: estudantes de biblioteconomia. Revista ACB. v. 13, n.1, p.130-144, 2008.

LAZZARINI, S. G. Estudos de Caso: aplicabilidade e limitações do método para fins de pesquisa. Economia e empresas, v. 2, n.4, p 17-26, 1995.

LUZ. R. Gestão do Clima Organizacional: Proposta de critérios para metodologia de diagnóstico, mensuração e melhoria. Estudo de caso em organizações nacionais e multinacionais localizadas na cidade do Rio de Janeiro. Niterói: 2003. Dissertação (Mestrado em Sistemas de Gestão). Universidade Federal Fluminense, 2003.

LUZ, R. Clima Organizacional. Rio de Janeiro: Qualitymark, 1995.

MACHADO, N. S.; SILVEIRA, A. Configurações estruturais em organizações universitárias. Florianópolis: Insular, 1998.

MAGRO, D. Um estudo sobre o clima organizacional da UDESC. Florianópolis: 2005. Dissertação (Mestrado em Administração). Universidade do Estado de Santa Catarina. Florianópolis, 2005.

MALHOTRA, N. F. N. Pesquisa de marketing: uma orientação aplicada. 4 ed. Porto Alegre: Bookman, 2006.

MEZOMO, J. C. Gestão da qualidade na escola: princípios básicos. São Paulo: Terra. 1994.

MOREIRA, D. A. (org.). Didática do Ensino Superior: Técnicas e Tendências. São Paulo: Pioneira, 1998.

MOTTA, K. A. M. B. A mediação do suporte na relação entre o estilo gerencial e o clima organizacional. Goiania: 2006. Dissertação (Mestrado em Psicologia). Universidade Católica de Goiás, 2006.

MULLER, M.; RAUSKI, E. F.; EYNG I. S.; MOREIRA, J. Comprometimento organizacional: um estudo de caso no supermercado "Beta". Revista Gestão Industrial, v. 4, n. 1, p. 511-518, 2005.

REGO, A.; SOUTO, S. A percepção de justiça como antecedente do comprometimento organizacional: um estudo luso-brasileiro. Revista de administração contemporânea, v. 1, n.8, p. 151-177, 2004.

RIZZATTI, G.; RIZZATTI Jr., G.; SARMENTO, J. V. S.; RIZZATTI, G.; RIZZATTI, C. E. Análise do clima organizacional de uma universidade federal brasileira: caso da 
Universidade Federal de Santa Catarina - UFSC. X Colóquio internacional sobre gestión en América Del Sur. Mar del Plata 8,9 y 10 de dezembro de 2010.

RIZZATTI, G. Categorias de análise de clima organizacional em Universidades Federais Brasileiras. Tese (Doutorado em Engenharia de Produção) - Universidade Federal de Santa Maria, Florianópolis, 2002.

RIZZATTI, G. Análise de fatores significativos do clima organizacional da UFSC: contribuição para implantação do programa de qualidade. Florianópolis: 1995. Dissertação (Mestrado em Engenharia de Produção). Universidade Federal de Santa Catarina, 1995.

LEITÃO, J. S.; GUIMARÃES, T. A.; ROSAL, M. A. Metodologia de Diagnóstico de Clima Organizacional em Ambiente de Inovação Tecnológica. In: ENCONTRO NACIONAL DOS PROGRAMASDE PÓS-GRADUAÇÃ̃ EM ADMINISTRAÇÃO, 1998, Foz do Iguaçu. Anais...Foz do Iguaçu: ANPAD, 1998. CD-ROM.

SANDES, W. F. Diagnóstico do Clima Organizacional da Polícia Militar do Estado de Mato Grosso. Monografia. Universidade Federal de Mato Grosso, 2001.

SCHNEIDER, B.; REICHERS, A. E. On the etiology of climates. Personnel Psychology, v.36, n.1, p.19-39, 1983.

SCHUCH JR, V. F. A estruturação da universidade em questão: o caso da UFSM. Revista Brasileira de Administração da Educação, v. 11, n. 2, 1995.

SANTOS, N. L, FARIA, L.; RURATO, P. Educação e aprendizagem de adultos: avaliação do auto-conceito de competência cognitiva e da auto-aprendizagem. In: V Congresso GalegoPortugués de Psicopedagoxía. v. 6, n. 4, p. 649-656, 2000.

SERCE. Segundo Estudo Regional Comparativo e Explicativo. Disponível em: <http://unesdoc.unesco.org/images/0016/001609/160926POR.pdf > Acesso em: 15 de ago. 2009.

SILVA, N. T. Uma proposta dos fatores a serem utilizados para avaliação do clima de uma instituição de ensino superior. Florianópolis: 2003. Dissertação (Mestrado em Engenharia de Produção). Universidade Federal de Santa Catarina. Florianópolis, 2003.

TOSCHI, E. O Espaço Intersubjetivo de Sala de Aula. In: SILVA, L. D.; POLENZ, T. (Org.). Educação e Contemporaneidade: Mudança de Paradigma na Ação Formadora da Universidade. Canoas: Ulbra, 2002.

WITTER, G. P. Produção científica. Campinas: Átomo, 1997. 